\title{
Promoting notification and linkage of HBs antigen and anti-HCV antibody-positive patients through hospital alert system
}

\author{
Naoki Yoshioka ${ }^{1 *}$, Akihiko Okumura', Yukie Yamamoto², Katsura Yamaguchi ${ }^{2}$ Atsuro Kaga', Kentaro Yamada', \\ Takuya Hirosaki ${ }^{1}$, Daisuke Ishikawa' ${ }^{1}$ Shin Kunii ${ }^{1}$, Kazumasa Watanabe', Setsuo Utsunomiya ${ }^{3}$, Kazuhiko Hayashi ${ }^{4}$, \\ Masatoshi Ishigami ${ }^{4}$, Hidemi Goto ${ }^{4}$ and Yoshiki Hirooka ${ }^{4}$
}

\begin{abstract}
Background: In Japan, approximately $0.9 \%$ and $1 \%$ of the whole population are infected with HBV and HCV, respectively. Doctors from departments other than gastroenterology often order viral hepatitis tests before an invasive examination or an operation. However, the notification of positive results to the patients and linkage to care is not appropriately performed. The in-hospital alert system was constructed to promote the notification and referral to gastroenterologists for patients with positive viral hepatitis tests, and its efficacy was evaluated.

Methods: The patients who tested HBsAg and anti-HCV antibody by chemiluminescent enzyme immunoassays and chemiluminescent immunoassays were investigated for whether they were notified of the positive results and if they were referred to gastroenterologists at our hospital. The notification and referral rate was compared before (from January to December 2014) and after the introduction of the alert system (from February to September 2016).

Results: HBsAg-positive rate was 1.1\% (69/6543) before the introduction of the alert system and $0.8 \%(41 / 5403)$ after it. The notification rate has significantly improved from $46 \%$ to $73 \%(p=0.0061)$ and the referral rate has improved from $16 \%$ to $27 \%$, while not significant. Positive rate of anti-HCV antibody was $2.1 \%$ (139/6481) before the introduction of the alert system and $2.4 \%(128 / 5322)$ after it. The rate of notification and referral has significantly improved from $35 \%$ to $62 \%(p<0.0001)$ and from $6 \%$ to $23 \%(p<0.0001)$, respectively.

Conclusions: The in-hospital alert system increased the rates of notification and referral of the patients with positive viral hepatitis tests. Enlightenment of doctors other than gastroenterologists on viral hepatitis and cooperation of medical staffs would be helpful to improve the notification and referral rates.
\end{abstract}

Keywords: Alert system, Hepatitis B virus, Hepatitis C virus, Notification and referral

\section{Background}

Viral hepatitis is a leading cause of death worldwide (1.45 million deaths in 2013) [1]. More than $90 \%$ of this burden is due to hepatitis B virus (HBV) and hepatitis C virus (HCV) as approximately 240 million individuals suffer from chronic hepatitis $B$, and 130-150 million suffer from chronic hepatitis $C[2,3]$. Without treatment, $20-30 \%$ of $\mathrm{HBV}$ - and $\mathrm{HCV}$-infected persons will develop

\footnotetext{
* Correspondence: town_court_2@yahoo.co.jp

${ }^{1}$ Department of Gastroenterology, The Aichi Prefectural Federation of Agricultural Cooperatives for Health and Welfare Kainan Hospital, 396 Minamihonden, Maegasu-cho, Yatomi, Aichi 498-8502, Japan

Full list of author information is available at the end of the article
}

hepatocellular carcinoma or cirrhosis, leading to an estimated 19 million deaths between 2015 and 2030 (11.8 million from HBV and 7.2 million from HCV) [4-6].

The World Health Organization made a commitment to eliminate viral hepatitis by 2030 at the World Health Assembly in 2016. Prevention and treatment strategies will increase the rate of treatment to $80 \%$ and reduce the number of annual deaths by $65 \%$, saving 7.1 million lives globally by 2030 [6].

In Japan, it was estimated that there were 1.1-1.2 million HBV-infected and 1.0-1.5 million HCV-infected individuals. Tanaka et al. estimated that approximately 0.48 million 
HBV-infected and 0.30 million $\mathrm{HCV}$-infected individuals remained unaware of their infection status in 2011 [7].

In Japan, doctors from departments other than gastroenterology often order a hepatitis B surface antigen (HBsAg) test and an anti-HCV antibody test before an invasive examination or an operation. However, the notification of positive results to the patients and linkage to care is not appropriately performed [8-10]. In this study, the rate of patient notification and gastroenterologist referral was assessed. The in-hospital alert system which promotes the notification and referral was constructed and the effects of the system were evaluated at our hospital.

\section{Methods}

\section{Subjects}

This was a single center study involving both inpatients and outpatients conducted at a tertiary care hospital. We searched the patients who tested HBsAg and anti-HCV antibody at departments other than the gastroenterology department through electric medical records. The records of the patients positive for HBsAg and anti-HCV antibody were examined whether they were notified the positive results, whether they were referred to gastroenterologists, and whether they received proper medical care. The rate of notification and referral was compared before (from January to December 2014) and after the introduction of the in-hospital alert system (from February to September 2016).

\section{The in-hospital alert system for promoting the notification of positive results and referral to gastroenterologists}

The medical technologists in the laboratory sent the following comments together with the positive results of the HBsAg or anti-HCV antibody tests: "Hepatitis virus test was positive. Please print the form and explain the positive results for the hepatitis virus infection to the patient." Within a week after the tests, the same comment was sent via e-mail to the doctors who ordered the hepatitis virus tests. Using the form, the doctors explained the positive results to the patients. After the patient had signed the form, the doctor captured it on the electronic medical records. The patients who wanted to see gastroenterologists were referred to one at our hospital. This alert system was constructed and became operational in February 2016.

\section{HBsAg and anti-HCV antibody tests}

At the preliminary investigation, $\mathrm{HBsAg}$ was measured using the Lumipulse II HBsAg (Fujirebio Inc., Tokyo, Japan), and anti-HCV antibody was measured using the Lumipulse II Ortho HCV (Fujirebio Inc., Tokyo, Japan). Both assays were chemiluminescent enzyme immunoassays. Following the introduction of the alert system, HBsAg was measured using the Architect HBsAg QT assay (Abbott Japan, Tokyo, Japan) and anti-HCV antibody was measured using the Architect $\mathrm{HCV}$ assay (Abbott Japan, Tokyo, Japan). Both assays were chemiluminescent immunoassays.

\section{Statistical analysis}

The statistical analysis was conducted using StatFlex ver. 6.0 software (Artech. Co., Ltd., Osaka, Japan). A chi-square test was used for categorical factors. Differences with $p$ values $<0.05$ were considered to be statistically significant. The difference of rates was also assessed by $95 \%$ confidential interval.

\section{Results}

\section{Preliminary investigation}

HBsAg was measured in 6543 patients, of whom 69 (1.1\%) were positive. Anti-HCV antibody was measured in 6481 patients, of whom 139 (2.1\%) were positive. The major departments where the hepatitis tests were undergone were emergency department, orthopedics department, and urology department. The positive rate for anti-HCV antibody was the highest in nephrology department (4.20\% [6/143]) (Table 1).

Of the patients positive for HBsAg and anti-HCV antibody, $42(61 \%)$ and $86(62 \%)$ were male, respectively. HBsAg-positive rates were $0.4 \%(1 / 224)$ in teens, $0.3 \%$ $(1 / 361)$ in 20 's, $0.7 \%(4 / 596)$ in 30 's, $0.9 \%(5 / 569)$ in 40 's, $2.2 \%(15 / 693)$ in 50 's, $1.5 \%(19 / 1267)$ in 60 s', $0.9 \%(14 /$ $1619)$ in 70s', and $1.2 \%(10 / 849)$ in 80 's. Anti-HCV antibody-positive rates were $0.5 \%(3 / 585)$ in 30 's, $1.3 \%$ $(7 / 551)$ in 40 's, $1.5 \%(10 / 687)$ in 50 's, $2.5 \%(32 / 1267)$ in 60 's, $2.8 \%(45 / 1615)$ in 70 's, $4.5 \%(38 / 850)$ in 80 's, and $2.9 \%(4 / 140)$ in 90 's.

A total of $46 \%(32 / 69)$ of the HBsAg-positive patients and $35 \%(48 / 139)$ of the anti-HCV antibody-positive patients were notified of the results (Fig. 1a and b). There were $16 \%(11 / 69)$ of the HBsAg-positive patients and $6 \%$ $(8 / 139)$ of the anti-HCV antibody-positive patients who were referred to gastroenterologists (Fig. 2a and b).

\section{HBsAg-positive patients after the introduction of the alert system}

HBsAg was measured in 5403 patients, of whom 41 $(0.7 \%)$ were positive. Of the HBsAg-positive patients, $73 \%(30 / 41)$ were notified of the results, which was a significantly higher rate than that before the introduction of the alert system (46\% [32/69]; 95\% confidential interval of difference of rate $=8 \% \sim 46 \% ; p=0.0061$ ) (Fig. 1a). There were 27\% (11/41) of the HBsAg-positive patients who were referred to gastroenterologists, a higher rate than that before the introduction of the alert system (16\% [11/69]), while there was no statistical significance (95\% confidential interval of difference of rate $=-5 \% \sim 26 \%)$ (Fig. $2 \mathrm{a})$. 
Table 1 Distribution of patients tested for HBsAg or anti-HCV antibody at departments other than the gastroenterology department

\begin{tabular}{|c|c|c|c|c|c|c|}
\hline \multirow[t]{2}{*}{ Department } & \multicolumn{3}{|l|}{$\mathrm{HBsAg}$} & \multicolumn{3}{|c|}{ anti-HCV antibody } \\
\hline & $\begin{array}{l}\text { Number of } \\
\text { patients tested }\end{array}$ & $\begin{array}{l}\text { Number of } \\
\text { positive patients }\end{array}$ & Positive rate (\%) & $\begin{array}{l}\text { Number of } \\
\text { patients tested }\end{array}$ & $\begin{array}{l}\text { Number of } \\
\text { positive patients }\end{array}$ & Positive rate (\%) \\
\hline emergency & 1318 & 16 & 1.21 & 1391 & 40 & 2.88 \\
\hline orthopedics surgery & 893 & 13 & 1.46 & 873 & 21 & 2.41 \\
\hline urology & 759 & 12 & 1.58 & 754 & 19 & 2.52 \\
\hline gastrointestinal surgery & 564 & 3 & 0.53 & 610 & 15 & 2.46 \\
\hline obstetrics and gynecology & 504 & 3 & 0.60 & 504 & 1 & 0.20 \\
\hline cardiology & 392 & 1 & 0.26 & 369 & 10 & 2.71 \\
\hline respiratory medicine & 345 & 6 & 1.74 & 336 & 12 & 3.57 \\
\hline otorhinolaryngology & 301 & 1 & 0.33 & 279 & 1 & 0.36 \\
\hline cranial nerve surgery & 293 & 1 & 0.34 & 279 & 1 & 0.36 \\
\hline plastic and reconstructive surgery & 242 & 2 & 0.83 & 251 & 3 & 1.20 \\
\hline ophthalmology & 185 & 0 & 0 & 197 & 4 & 2.03 \\
\hline dermatology & 178 & 2 & 1.12 & 123 & 2 & 1.63 \\
\hline nephrology & 150 & 1 & 0.67 & 143 & 6 & 4.20 \\
\hline rheumatology & 73 & 1 & 1.37 & 61 & 0 & 0 \\
\hline hematology & 64 & 1 & 1.56 & 51 & 1 & 1.96 \\
\hline dental surgery & 63 & 1 & 1.59 & 63 & 0 & 0 \\
\hline general medicine & 57 & 2 & 3.51 & 50 & 2 & 4.00 \\
\hline neurology & 49 & 1 & 2.04 & 48 & 1 & 2.08 \\
\hline pediatrics & 34 & 1 & 2.94 & 21 & 0 & 0 \\
\hline diabetes medicine and endocrinology & 34 & 0 & 0 & 31 & 0 & 0 \\
\hline cardiovascular surgery & 29 & 1 & 3.45 & 29 & 0 & 0 \\
\hline medical oncology & 6 & 0 & 0 & 8 & 0 & 0 \\
\hline geriatrics & 5 & 0 & 0 & 4 & 0 & 0 \\
\hline anesthesiology & 4 & 0 & 0 & 5 & 0 & 0 \\
\hline psychiatry & 1 & 0 & 0 & 1 & 0 & 0 \\
\hline Total & 6543 & 69 & 1.05 & 6481 & 139 & 2.14 \\
\hline
\end{tabular}

A total of 11 patients consulted gastroenterologists. Of these, seven patients initiated nucleoside/nucleotide analogues (NAs) therapy because of their chemotherapy or immunosuppressive therapy, three patients were diagnosed as asymptomatic carriers, and one patient declared no wish to receive an examination or treatment.

There were 19 patients who were notified of the positive results but were not referred to a gastroenterologist. Of these, three patients were not with proper care (Table 2).

\section{Anti-HCV antibody-positive patients after the introduction of the alert system}

Anti-HCV antibodies were measured in 5322 patients, of whom 128 (2.4\%) were positive. There were 62\% (79/128) of the anti-HCV antibody-positive patients who were notified of the positive results, a significantly higher rate than that before the introduction of the alert system
(35\% [48/139]; 95\% confidential interval of difference of rate $=15 \% \sim 39 \% ; p<0.0001)$ (Fig. 1b). A total of 23\% (30/ 128 ) of the anti-HCV antibody-positive patients were referred to gastroenterologists, which was a significantly higher rate than that before the introduction of the alert system (6\% [8/139]; 95\% confidential interval of difference of rate $=9 \% \sim 26 \% ; p<0.0001)$ (Fig. 2b).

There were 30 patients who consulted gastroenterologists. Of these, three patients started interferon-free treatment; one patient began taking ursodeoxycholic acid, twenty-one patients were found to be negative for $\mathrm{HCV}$ RNA, and five patients declared no wish to receive an examination or treatment.

A total of 49 patients were notified of the positive results but were not referred to the gastroenterologists. Of these, 13 patients were not with proper care, seven of which declared no wish to receive an examination or 


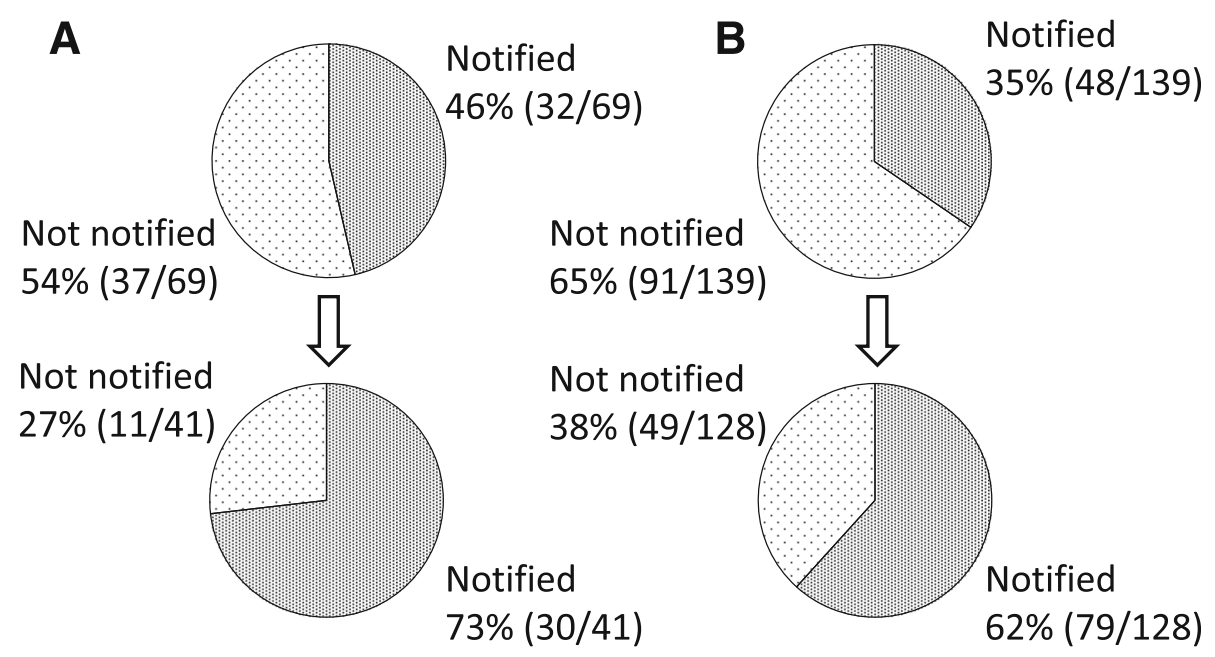

Fig. 1 The rate of HBsAg or anti-HCV antibody-positive patients who were notified of the results before and after the introduction of the alert system. a The rate of HBsAg-positive patients who were notified of the positive results increased significantly after the introduction of the alert system (95\% confidential interval of difference of rate $=8 \% \sim 46 \% ; p=0.0061)$. b The rate of anti-HCV antibody-positive patients who were notified of the results increased significantly after the introduction of the alert system ( $95 \%$ confidential interval of difference of rate $=15 \% \sim 39 \% ; p<0.0001$ )

treatment (Table 3). Of seven patients who declared no wish to receive an examination or treatment, one patient complained that a general practitioner told him the possible severe side effects caused by interferon-free treatment, and two patients (a 70-year-old man and an 86year-old woman) complained that they were very old and their liver function was stable. The reason for the declaration of no wish to receive an examination or treatment in the other four patients remains unknown.

\section{Discussion}

The in-hospital alert system was constructed to promote doctors other than gastroenterologists to appropriately notify and refer patients with positive viral hepatitis tests to gastroenterologists. The system increased the rate of notification for the HBsAg (from 46 to $73 \%$ ) or for anti$\mathrm{HCV}$ antibody (from 35 to $62 \%$ ) tests, and the rate of referral for HBsAg (from 16 to $27 \%$ ) or for anti-HCV antibody (from 6\% to $23 \%$ ) tests.

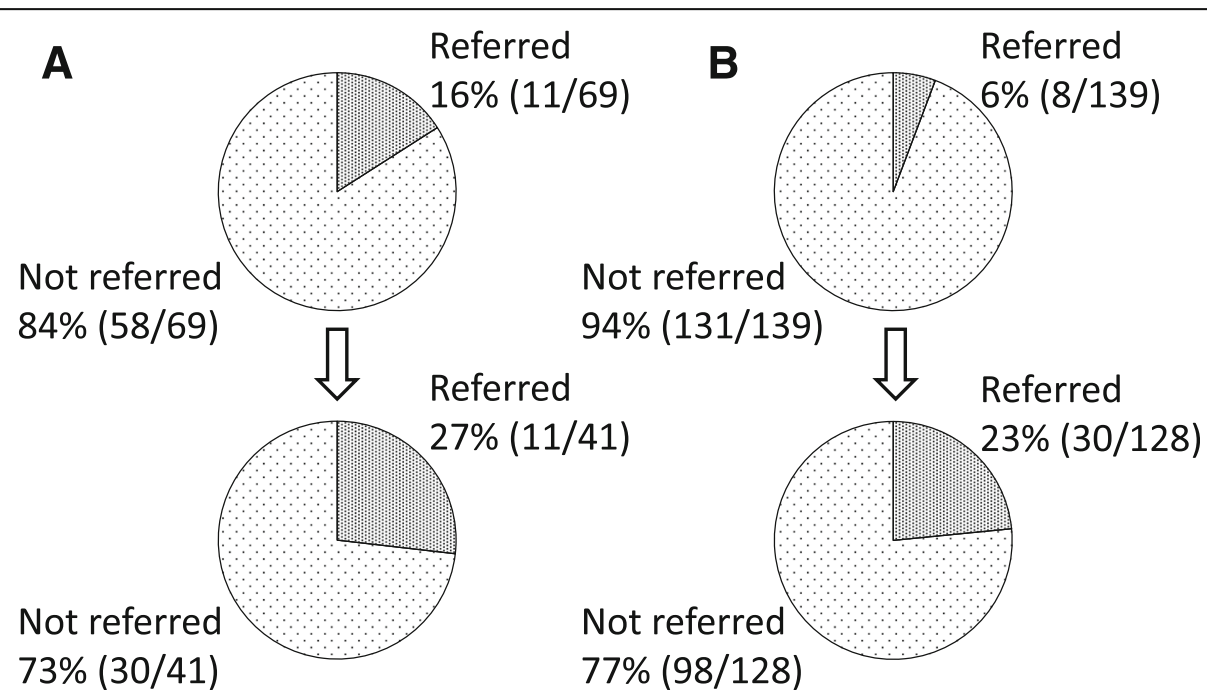

Fig. 2 The rate of HBsAg or anti-HCV antibody-positive patients who were referred to a gastroenterologist before and after the introduction of the alert system. a The rate of HBsAg-positive patients who were referred to gastroenterologists increased after the introduction of the alert system, while there was no statistical significance ( $95 \%$ confidential interval of difference of rate $=-5 \% \sim 26 \%$ ). $\mathbf{b}$ The rate of anti-HCV antibody-positive patients who were referred to a gastroenterologist increased significantly after the introduction of the alert system $(95 \%$ confidential interval of difference of rate $=9 \% \sim 26 \% ; p<0.0001$ ) 
Table 2 State of medical care of 19 patients who were notified of HBsAg-positive results but were not referred to the gastroenterologists

\begin{tabular}{lc}
\hline State of medical care & $\begin{array}{l}\text { Number of } \\
\text { patients }\end{array}$ \\
\hline With proper care & 16 \\
Undergoing nucleoside/nucleotide analogues therapy & 12 \\
Seeing gastroenterologists at our hospital & 2 \\
Attending other general hospitals & 2 \\
Without proper care & 3 \\
Seeing a pediatrician at our hospital & 1 \\
Seeing a general practitioner at other clinic & 1 \\
Declared no wish to receive an examination or treatment & 1 \\
\hline
\end{tabular}

There were only two previous reports about in-hospital alert system. Shimomura et al. reported that a fully automated reporting system on electronic medical records increased the rate of notification for patients positive for viral hepatitis tests (from 29 to 58\%) [9]. Fujii et al. reported that an alert system consisting of putting "sticky notes" on the electronic medical records increased the referral rate of the HBsAg-positive patients from 14\% to $48 \%$ and that of anti-HCV antibody-positive patients from 7 to $51 \%$ [10]. Thus, these alert systems are useful for increasing the number of notifications and referrals to specialists for patients with positive results of viral hepatitis test.

The referral rate of the present study was apparently lower than that of Fujii et al. We assessed the state of medical care of the patients with notification but without referral. 16\% (3/19) of HBsAg-positive patients and $27 \%(13 / 49)$ of anti-HCV antibody-positive patients did not receive proper care, while 84 and $73 \%$ received proper care, respectively. The low rate of referral may be

Table 3 State of medical care of 49 patients who were notified of anti-HCV antibody-positive results but were not referred to the gastroenterologists

\begin{tabular}{ll}
\hline State of medical care & $\begin{array}{l}\text { Number of } \\
\text { patients }\end{array}$ \\
\hline With proper care & 36 \\
HCV RNA negative without antiviral therapy & 9 \\
Sustained virological response after antiviral therapy & 13 \\
Under interferon-free treatment & 4 \\
Seeing gastroenterologists at our hospital & 6 \\
Attending other general hospitals & 4 \\
Without proper care & 13 \\
Seeing a surgeon at our hospital & 1 \\
Seeing general practitioners at other clinics & 5 \\
Declared no wish to receive an examination or treatment & 7 \\
\hline
\end{tabular}

attributed to the high rate of proper care in those with notification but without referral.

In United States of America, Hepatitis Testing and Linkage to Care (HepTLC) initiative of the Center for Disease Control and Prevention provided financial supports to organizations to offer testing and test result notification to people at risk for HBV and/or HCV infection [11]. Of the 4766 people who tested positive for either HBV or HCV infection, 2116 (44\%) were linked to care. It is suggested that patient navigation by counselors was critical for follow-up and linkage to care. In our hospital, medical counselors would be helpful to deliver the patients the information of viral hepatitis and to raise the rate of referral.

We found that the findings that some patients did not receive proper care were attributed to the inappropriate knowledge of the doctors other than gastroenterologists and patients. Thus, enlightenment of the doctors on viral hepatitis is needed. Patient navigation by medical counselor is also needed.

In the alert system, the medical technologists in the laboratory send a comment which recommends the notification and referral together with the positive results of viral hepatitis test, and send the same comment via e-mail within a week after the test results. The alert system was constructed by both doctors and medical technologists. Therefore, the medical technologists became familiar with viral hepatitis and made a greater effort to provide appropriate care to patients with viral hepatitis. To provide appropriate care to the patients, it is important to gather the support of all medical staff. The construction of the alert system provided such an opportunity to involve medical staffs other than doctors.

Today, chronic hepatitis with HBV and HCV can both be treated with highly effective medicines [12-15]. Thus, the early detection and linkage to proper care have become increasingly important [16-18]. The Ministry of Health, Labor and Welfare has implemented the recommendation to inform all Japanese citizens of the necessity of undergoing hepatitis tests at least once, and such tests are free [19]. However, the rate of tests for HBV or HCV is low (57.7 or $48.1 \%$, respectively) [20]. Thus, it is important that when patients are found positive for HBsAg or anti-HCV antibody in the hospital, notification and referral to a gastroenterologist should be securely performed.

\section{Conclusions}

The alert system has increased the rates of notification and referral. It is demonstrated that many of the patients positive for viral hepatitis test with notification received proper care even without referral to gastroenterologists in our hospital. However it is necessary to raise the rate of notification and referral further. The enlightenment of doctors other than gastroenterologists on viral hepatitis 
and cooperation of medical staffs would be helpful to raise the notification and referral rate.

\section{Abbreviations}

HBV: hepatitis B virus; HCV: hepatitis C virus; HBsAg: hepatitis B surface antigen; SVR: sustained virological response

\section{Acknowledgements}

No additional acknowledgments.

\section{Funding}

The authors declare that they have no funding sources.

\section{Availability of data and materials}

The datasets used and/or analyzed during the current study are available from the corresponding author on reasonable request.

\section{Authors' contributions}

NY analyzed, summarized, interpreted the data, and drafted the manuscript AO contributed to critical revision. YY, KY, AK, KY, TH, DI, SK, KW, and SU collected the data. $\mathrm{KH}, \mathrm{MI}, \mathrm{HG}$, and $\mathrm{YH}$ contributed to the interpretation of the data. All authors read and approved the final manuscript.

\section{Competing interests}

The authors declare that they have no competing interests.

\section{Consent for publication}

Not applicable.

\section{Ethics approval and consent to participate}

The study protocol was approved by the Institutional Review Board at Kainan Hospital (290112-01), and the study was conducted in accordance with the concepts outlined in the Declaration of Helsinki. The Institutional Review Board gave permission to collect data without informed consent.

\section{Publisher's Note}

Springer Nature remains neutral with regard to jurisdictional claims in published maps and institutional affiliations.

\section{Author details \\ ${ }^{1}$ Department of Gastroenterology, The Aichi Prefectural Federation of Agricultural Cooperatives for Health and Welfare Kainan Hospital, 396 Minamihonden, Maegasu-cho, Yatomi, Aichi 498-8502, Japan. ²Department of Medical Technology, The Aichi Prefectural Federation of Agricultural Cooperatives for Health and Welfare Kainan Hospital, 396 Minamihonden, Maegasu-cho, Yatomi, Aichi 498-8502, Japan. ${ }^{3}$ Department of Medical Oncology, The Aichi Prefectural Federation of Agricultural Cooperatives for Health and Welfare Kainan Hospital, 396 Minamihonden, Maegasu-cho, Yatomi, Aichi 498-8502, Japan. ${ }^{4}$ Department of Gastroenterology and Hepatology, Nagoya University Graduate School of Medicine, 65 Tsurumai-cho, Showa-ku, Nagoya 466-8550, Japan.}

Received: 28 February 2017 Accepted: 2 May 2017

Published online: 08 May 2017

\section{References}

1. Stanaway JD, Flaxman AD, Naghavi M, Fitzmaurice C, Vos T, Abubakar I, et al. The global burden of viral hepatitis from 1990 to 2013: findings from the global burden of disease study 2013. Lancet. 2016;388(10049):1081-8.

2. Ott JJ, Stevens GA, Groeger J, Wiersma ST. Global epidemiology of hepatitis $B$ virus infection. New estimates of age-specific HBsAg seroprevalence and endemicity. Vaccine. 2012;30(12):2212-9.

3. Mohd Hanafiah K, Groeger J, Flaxman AD, Wiersma ST. Global epidemiology of hepatitis C virus infection. New estimates of age-specific antibody to HCV seroprevalence. Hepatology. 2013;57(4):1333-42.

4. Terrault NA, Bzowej NH, Chang KM, Hwang JP, Jonas MM, Murad MH. AASLD guidelines for treatment of chronic hepatitis B. Hepatology. 2016;63(1):261-83.

5. Hepatitis C. Guidance: AASLD-IDSA recommendations for testing, managing, and treating adults infected with hepatitis C virus. Hepatology. 2015;62(3):932-54.
6. Combating hepatitis B and C to reach elimination by 2030. World Health Organization. http://apps.who.int/iris/bitstream/10665/206453/1/WHO_HIV 2016.04_eng.pdf. Accessed 27 May 2016.

7. Tanaka J. the 13th Council on Promotion of Hepatitis Measures. http://www. mhlw.go.jp/file/05-Shingikai-10905750-KenkoukyokuKanentaisakusuishinshitsu/0000075723.pdf. Accessed 26 Feb 2015.

8. Furukawa N, Kawaguchi Y, Oeda S, Izumi N, Eguchi H, Mizuta T, et al. Current management practices for HBs antigen or anti-HCV antibody positive individuals in non-hepatology departments at a university hospital. Kanzo. 2013;54(5):307-16

9. Shimomura Y, Ikeda F, Nouso K, Takaki A, Watanabe T, Iwatsuki K, et al. Introduction of management system of positive test results for $\mathrm{HBV}$ and HCV infection in electronic medical chart. Kanzo. 2015;56:137-43.

10. Fujii H, Yamaguchi S, Kurai O, Miyano M, Ueda W, Oba H, et al. Putting "sticky notes" on the electronic medical record to promote intra-hospital referral of hepatitis B and C virus-positive patients to hepatology specialists: an exploratory study. BMC Infect Dis. 2016:16:410.

11. Ramirez G, Cabral R, Patterson M, Schoenbachler BT, Bedell D, Smith BD, et al. Early identification and linkage to Care for People with chronic HBV and HCV infection: the HepTLC initiative. Public Health Rep. 2016;131(Suppl 2):5-11.

12. Hosaka T, Suzuki F, Kobayashi M, Seko Y, Kawamura Y, Sezaki H, et al. Long-term entecavir treatment reduces hepatocellular carcinoma incidence in patients with hepatitis B virus infection. Hepatology. 2013;58(1):98-107.

13. Omata M, Nishiguchi S, Ueno $Y$, Mochizuki H, Izumi N, Ikeda F, et al. Sofosbuvir plus ribavirin in Japanese patients with chronic genotype $2 \mathrm{HCV}$ infection: an open-label, phase 3 trial. J Viral Hepat. 2014;21(11):762-8.

14. Mizokami M, Yokosuka O, Takehara T, Sakamoto N, Korenaga M, Mochizuki $\mathrm{H}$, et al. Ledipasvir and sofosbuvir fixed-dose combination with and without ribavirin for 12 weeks in treatment-naive and previously treated Japanese patients with genotype 1 hepatitis C: an open-label, randomised, phase 3 trial. Lancet Infect Dis. 2015;15(6):645-53.

15. Kumada H, Suzuki F, Suzuki Y, Toyota J, Karino Y, Chayama K, et al. Randomized comparison of daclatasvir + asunaprevir versus telaprevir + peginterferon/ribavirin in Japanese hepatitis C virus patients. J Gastroentero Hepatol. 2016;31(1):14-22.

16. Liaw YF. Natural history of chronic hepatitis B virus infection and long-term outcome under treatment. Liver Int. 2009:29(Suppl 1):100-7.

17. Sroczynski G, Esteban E, Conrads-Frank A, Schwarzer R, Muhlberger N, Wright $D$, et al. Long-term effectiveness and cost-effectiveness of screening for hepatitis C virus infection. Eur J Pub Health. 2009;19(3):245-53.

18. Mitchell $\mathrm{AE}$, Colvin HM, Palmer BR. Institute of Medicine recommendations for the prevention and control of hepatitis B and C. Hepatology. 2010; 51(3):729-33

19. Basic Act on Hepatitis Measures. Ministry of Justice. 2009. http://www. japaneselawtranslation.go.jp/law/detail/?id=1995. Accessed 4 Dec 2009.

20. Kaishima T, Fujii T, Matsuoka T, Sakamune K, Nagashima S, Yamamoto C, et al. Study of the issues of receiving hepatitis screening and the rate of consulting hospitals-the rate of recognized receiving hepatitis screening and that of the unrecognized. Kanzo. 2016;57(12):634-48. 